Mohamed Tanta, Vítor Monteiro, Tiago J. C. Sousa, Antonio P. Martins, Adriano S. Carvalho and João L. Afonso

"Power Quality Phenomena in Electrified Railways: Conventional and New Trends in Power Quality Improvement toward Public Power Systems"

In the 2nd International Young Engineers Forum on Electrical and Computer Engineering, YEF-ECE 2018, p.p 25-30, 4 May 2018, Costa da Caparica, Portugal.

ISBN: 978-1-5386-1504-1.

DOI: 10.1109/YEF-ECE.2018.8368934. 


\title{
Power Quality Phenomena in Electrified Railways: Conventional and New Trends in Power Quality Improvement toward Public Power Systems
}

\author{
Mohamed Tanta ${ }^{1}$, Vítor Monteiro ${ }^{1}$, Tiago J. C. Sousa ${ }^{1}$, António P. Martins ${ }^{2}$ \\ Adriano S. Carvalho ${ }^{2}$ and João L. Afonso ${ }^{1}$ \\ ${ }^{1}$ Centro ALGORITMI - University of Minho, Guimarães - Portugal \\ ${ }^{2}$ SYSTEC Research Center - University of Porto, Porto - Portugal
}

\begin{abstract}
Nowadays, railway electrification is the most efficient way to power the trains. However, power quality $(P Q)$ phenomena toward public power systems (PPSs) have always a main concern to the railway operators, especially when the single-phase traction power system is interconnected to the three-phase PPS. The last decades have witnessed an on-going evolution of PQ improvement and traction power supply systems, contributing to diminish the negative impacts of AC railway networks on PQ of the three-phase PPS. In this context, this paper presents a global overview of the PQ phenomena in AC railway electrification, as well as the impacts of the potential hazards on the safe operation of electrified railways. The paper also reviews $P Q$ improvement methods from the early use of $\mathrm{AC}$ railway electrification until the emergence of the new power electronics devices in railways industry.
\end{abstract}

Keywords-Negative Sequence Components (NSCs); Power Quality (PQ); Public Power System (PPS); Traction Power System (TPS).

\section{INTRODUCTION}

Railway electrification has been set out in the early of $20^{\text {th }}$ century. It was undertaken in many countries because of its advantages such as the lower air pollution, the higher efficiency, and the reduced Carbon Dioxide emissions [1]. From the early use of railway electrification, the power quality (PQ) improvement was a significant concern for the railway operators and the scholars. Therefore, many research studies have been devoted for this purpose. Nowadays, most of the high-speed electric trains are using the AC power for a long-distance electrification [2]. The single-phase AC traction power system (TPS) is connected through several power transformers to the three-phase public power system (PPS). Consequently, the electrified railways are causing significant harmonic distortion and unbalance in voltages and in currents on both PPS and TPS. However, the PQ improvement on TPS was not under interest because the traction load has a poor PQ by nature [3], and most of PQ studies in AC railway electrification are focusing on the PQ improvement of the PPS.

In this context, this paper presents an overview of the PQ issues in railway electrification, as well as the PQ improvement methods that can be either traditional ones or based on the new power electronics technology. [2]. The main contribution of this paper is to present an overview of the PQ phenomena in AC railway electrification, as well as the innovative methods used for PQ improvement.

The paper is organized as follows: Section II describes the PQ phenomena in AC railway electrification, Section III presents the hazards associated to the PQ deterioration in AC railway electrification. Section IV discusses the conventional PQ compensation methods. Section V presents the PQ compensation methods based on power electronics compensators. Finally, section VI summarizes the conclusion of the work.

\section{PQ PHENOMENA IN AC RAILWAY ELECTRIFICATION}

The typical PQ problems in high-speed electrified railways are the system currents imbalance, harmonic content, low power factor, low-frequency voltage fluctuations and the voltage arcing [1]. The next subsections present a described overview of the PQ problems in electrified railways.

\section{A. Currents Imbalance}

The PPS is considered balanced when the three-phase voltages and currents are sinusoidal and have the same amplitude with a phase angle difference of $120^{\circ}$. However, in AC railway electrification, the NSCs of voltages are normally negligible since the TPS is connected to an infinite bus-bar of the PPS through several power transformers [1]. It is expected that the infinite bus-bar has always constant RMS voltage values. Therefore, system imbalance in AC railway electrification usually refers to the NSCs of currents injected in the PPS [1]. Considering the other possibility, which could happen when the TPS is not connected to an infinite bus-bar, then, voltage drops in the three-phase system will be noticeable. Using uncontrolled loads, the three-phase voltage unbalance will result in three-phase currents imbalance. In other words, the NSCs of voltages will produce the NSCs of currents as well [3]. The traction motors of electric locomotives are normally designed to properly operate at reduced voltage amplitude by $24 \%$, or at bigger amplitudes by $10 \%$, than the nominal voltage [3]. Hence, currents imbalance has more priority to be solved than the voltage problems in AC railway electrification.

\section{B. Harmonic Content}

Electric locomotives are normally using the AC/DC/AC power converters to drive the traction motors. However, these 
converters, especially the old half-controlled ones, are causing different harmonic content that flow into the PPS [4], [5]. There will be a series of harmonic components that have the double, third, fourth, etc., of the fundamental frequency. Among them, the most dangerous is the 3rd order harmonic. In the three-phase four-wire systems, the 3rd order harmonics are generated when unbalanced nonlinear loads (e.g., electric locomotives) are under operation [1]. Harmonic distortion is considered as the second main factor for PQ deterioration in railway electrification. The power system may have a harmonic resonance frequency because of the interaction between the transmission lines inductive and capacitive reactances. However, a related point to consider is the harmonic problem can be worsened when the harmonic resonance may occur, once the harmonic currents injected by the locomotives match one or more of the power system natural frequencies (the natural frequency refers to a value at which the electric power system tends to perform the resonance phenomenon) [1], [6]. In such situations, harmonic distortion will increase to reach high levels and the harmonic resonance will happen accompanied by large waveform oscillations of amplitude. This scenario leads to serious impacts on both PPS and TPS, and it may cause the total collapse of the adjacent power devices, especially on the TPS side [6].

\section{Power Factor}

A low power factor value indicates a high amount of reactive power, which is an amount of the exchanged energy between the PPS and the reactive part of the TPS. The reactive power is necessary for the traction system operation, but it should be reduced as much as possible to reduce the operating costs of the electric trains [7]. Nowadays, the new locomotives contain power electronics converters controlled by a pulse width modulation technique and they produce zero reactive power [3]. Regarding the TPS, reactive power is required to compensate the NSCs of currents, hence, a contradiction between the NSCs compensation and the reactive power compensation may occur [4]. Therefore, the NSCs in the single-phase TPS must be in antiphase with the three-phase voltages/currents of the PPS [3]. As a result, the reactive power and the NSCs compensation are performed jointly.

\section{Low-Frequency Voltage Fluctuations}

These fluctuations indicate the voltages with a low-frequency equal or less than $10 \mathrm{~Hz}$ when the fundamental frequency is equal to $50 \mathrm{~Hz}$ [1]. In some cases, the fluctuations could trigger the locomotives protection devices to disconnect the train. It is hard to know the direct reason for the low-frequency voltage fluctuations, where this topic did not take enough attention by the researchers. However, the fluctuations, in fact, could appear as a complicated locomotive-grid interaction problem [8], [9], and they have been noted worldwide in a variety of AC locomotives and at different operating conditions. According to the published literature, this phenomenon was first noted in a Norwegian railway, where the rotary converters were used in the TPS substations. The fluctuations have been distinguished later in Germany, Switzerland, France, China and USA. The problem in France and China occurred due to the same reasons, in which many electric locomotives were totally under a standstill state in the railway stations with only the auxiliary load powered by the DC-link of the AC/DC/AC converters [8]. A study has been performed in [9] on a traction substation in China that extremely suffered from the low-frequency voltage fluctuations. The scholars have concluded that, the fluctuations were caused by the current collectors of the Chinese HXD2B locomotives.

\section{E. Voltage Arcing}

Voltage arcing is partially an unavoidable problem in railway electrification and it is normally more predominant at high-speed trains [10]. This phenomenon occurs because of the interaction between the pantograph and the overhead line or between the brushes and the third/fourth rail. The main reason of the voltage arcing in railway electrification is the varied airgap due to the train mechanical oscillations [3]. The arcs increase at a subzero temperature, where a skinny ice layer isolates and prevents the direct contact between the pantograph and the catenary line. Since the voltage level in the DC railway electrification is lower than the one in AC railways, the produced current is always higher, the arcs are stronger, and the electromagnetic interference radiation is more intense in the DC railway electrification [11]. Therefore, visible and bright arcs moving along the pantograph or along the brushes are well noticed in the DC rails underground metros.

\section{HAZARDS OF PQ DETERIORATION}

The effects of PQ deterioration vary according to the type of active PQ problems. For instance, a high-risk factor is considered in the case of three-phase currents imbalance. PQ deterioration can be seriously hazardous, without forgetting the potential great financial damages as well [3]. Next subparagraphs give an overview of PQ deterioration impacts on PPS, communication system and the electric locomotives.

\section{A. Impacts on Electric Power Systems}

Since the traction load is a huge single-phase load connected to the three-phase PPS, the NSCs of currents injected in the PPS are existing by default. If the NSCs are not compensated, then they will flow in the phases, increasing the heat losses of the transmission lines. The synchronous generators will also suffer from the NSCs of currents, in which the rotors parts will be overheated, resulting in additional losses and mechanical stress of generators [12]. In addition, NSCs of currents may lead to overheat the power transformers windings, decreasing the total loading capacity of power transformers [12].

The electric locomotives power converters are the main responsible for the harmonic distortion. However, and in case of harmonics allowance, they will cause additional heat losses in the transmission lines, synchronous generators, and the power transformers, followed by additional noise [1]. On the other hand, a failure or a wrong response of the protection relays devices may occur, especially at a high-level of harmonics. When a harmonic resonance happens, which is the most serious scenario, the resonance may saturate the transformer core of the measuring transformers in the power substation, which will decrease the measurement accuracy [1].

As aforementioned, a low power factor indicates a high amount of reactive power. However, if the reactive power ratio in the PPS is more than 10-20\% of the apparent power, this leads to decrease the loading capacity of the generators [12]. The costs of electricity generation and the transmission lines are also 
increased. Furthermore, the currents and the voltage drops in the power transmission lines increase.

Finally, the voltage arcs can distort the voltage and current waveforms, in which they may deteriorate the PQ during specific transient periods [10]. In addition, a transient current component in the TPS could be produced and trigger one or more of the protection relays to disconnect the main feeder lines of the electric locomotive.

\section{B. Impacts on Signaling and Communication Systems}

The circuits of communication and signaling systems are designed to operate at a high frequency (higher than the fundamental frequency), different from the power fundamental frequency to avoid any possible interference. However, if the power system suffers from a high harmonic ratio, the high-order harmonic frequencies may disturb the communication signals, resulting in incorrect values and a fault in train monitoring [3], which could lead to a catastrophe. The voltage arcs are the main reason for the stray currents. However, and since the communication cables usually lie in parallel close to the power cables, the stray currents may generate magnetic fields in the communication cables and induce voltages that pollute the communication signal [3], [11].

\section{Impacts on Electric Locomotives}

The NSCs of currents will induce double frequency currents in the rotors surface of the induction motors used in traction. Consequently, this may increase the rotor temperature and it will harm the machine at the long-term use. On the other hand, the NSCs of currents can create a magnetic flux in the rotor that opposes the main rotation direction, whereby the torque produced by the traction motors will be reduced [12]. In addition, and since the induction motors torque value is proportional to the square value of the applied RMS voltage, any voltage oscillations will directly be reflexed on the torque characteristics of the induction motors.

\section{PQ IMPROVEMENT IN ELECTRIFIED RAILWAYS: CONVENTIONAL METHODS}

From the early use of railway electrification, several methods have been applied and investigated to overcome the PQ deterioration on PPS side. The following techniques have been put in service several decades ago, and for the time being, they are still used worldwide in several traction substations. Next subsections outline a summary of the traditional methods that have been applied in order to improve the PQ.

\section{A. Three-Phase Electric Trains}

The three-phase asynchronous motors were universally used in the last decades for traction applications. Therefore, some of TPSs have been created under the three-phase AC power with two catenary lines plus the third and/or the fourth rail. The main complexity of this system was the need for three conductors, which highly increased the total costs. Italy was the major user for the three-phase AC traction system under the frequency of $16.7 \mathrm{~Hz}$ and voltage around $3.6 \mathrm{kV}$ for the mountain lines [3]. Since the traction load in this case is a three-phase one, the main advantage of this system was the negligible NSCs of currents injected in the PPS. However, using the second pantograph and electrifying the rails were the main reasons to abandon this approach.

\section{B. Phase-Shift Method Using Adjacent Power Transformers}

In this method, the overhead catenary lines are sectionized in electrically isolated parts to avoid short circuits between phases. The non-electrified zones are called the neutral sections (NSs), and their length varies between several meters up to some kilometers [13]. Each zone along the catenary line is a single-phase one and the alternation between phases normally occurs at each traction substation. This is an old and economical way to achieve balance between phases [14]. However, when the electrified sections are not equally loaded, the NSCs of currents are relatively reduced, but they remain as a result of asymmetrical three-phase currents [3]. The alternation between phases does not totally solve the problem of currents imbalance unless the loads of each electrified section are equal. In addition, this topology prevents load sharing between the adjacent single-phase power transformers. Fig 1 demonstrates the phase-shift method in three single-phase traction substations.

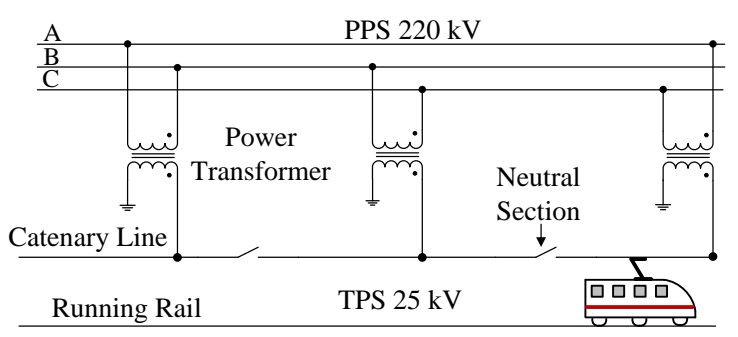

Fig. 1. Phase-shift method to alternate between PPS phases.

\section{Using Balanced Three-Phase Power Transformers}

Some special types of three-phase power transformers are familiar to be used in two-phase power connections and in rail distribution networks. This is due to some technical characteristics that can help in PQ improvement, such as the ability to reduce the NSCs on the PPS side. Among the most commonly used balanced transformers are the Scott, the LeBlanc, the impedance matching and the Woodbridge power transformers. The NSCs of currents injected in the PPS are neglected when the electrified sections have the same loads [15]. Regarding the harmonic distortion, balanced transformers can be an interesting choice, since they can lead to some harmonics cancellation [6]. However, and after considering the facts of complex winding configurations and an unequal number of turns on each phase, these reasons can cause non-perfect balanced situation even when the load sections are equally loaded [3]. There are some disadvantages that should be respected when using the balanced power transformers. Initially, the material (iron and copper) utilization factors of these power transformers are relatively low comparing to the normal unbalanced $\mathrm{V} / \mathrm{V}$ power transformers. In addition, the required voltage insulation level is high and expensive for the Scott and LeBlanc power transformers, since there is no neutral point in the primary windings of these power transformers [16]. Fig 2(a) shows Scott power transformer connections, whereas Fig 2(b) presents LeBlanc power transformer. The impedance matching power transformer presented in Fig 2(c) is the most used one in China. Woodbridge power transformer normally requires two additional autotransformers for the two-phase railway traction 
power supply [6], [16]. The unbalanced V/V power transformer has a very simple construction comparing to the balanced power transformers and it can be overloaded [4]. Therefore, it is widely used in the railway applications.

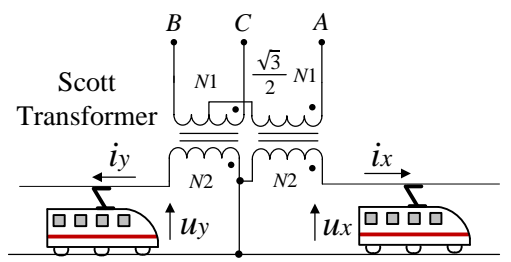

(a)

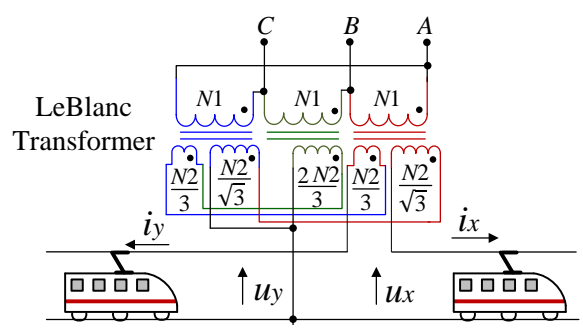

(b)

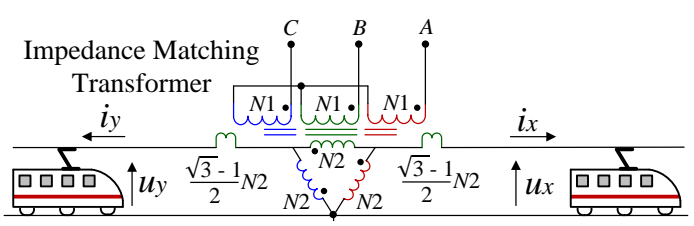

(c)

Fig. 2. Balanced railway power transformers; (a) Scott transformer; (b) LeBlanc transformer; (c) Impedance matching transformer.

\section{Using Passive Power Filters}

Passive filters present a simple structure, containing passive elements such as inductors and capacitors. These filters were firstly used in 1940 to reduce the injection of harmonic currents from locomotive converters to the TPS [17]. This was the typically used method for harmonic reduction and power factor correction in railway electrification. Normally, these passive power devices can be used in conjunction with a balanced power transformer or power electronics compensators to reduce the compensator power ratings, costs, and volume [6]. There are many types of passive power filters, such as the single-tuned, double-tuned or third-tuned ones [1]. In general, these types of filters can diminish the low-order harmonic content (e.g., $5^{\text {th }}$ and $7^{\text {th }}$ ), whereas the damping passive filter has been proposed to eliminate higher order harmonics [1]. In order to limit the harmonic distortion to an allowable level, installing passive filter banks linked in parallel was the recommended solution to perceive the filtering effect, which might require a large space for installation, besides the high implementation costs [1]. Another problem was related to the change in the filter parameters affected by the heat or lifetime, which gradually caused misoperations in the filter functionality. It is noteworthy that the compensation system, when using the passive power filters, cannot reach a unitary power factor correction, as long as the reactive power of the TPS changes frequently. The fixed capacitor value in each passive filter cannot totally compensate the reactive power, since these devices are not able to follow the dynamic changes in time [1].

\section{PQ IMPROVEMENT IN ELECTRIFIED RAILWAYS: POWER ELECTRONICS TECHNOLOGY-BASED METHODS}

In order to implement a dynamic compensation, new power compensators based on power electronics technology were put in service since the 1970s [17], especially after the registered evolution in power electronics devices. This section presents the power electronics-based methods that are using to improve the PQ of the PPS.

\section{A. Static VAr Compensator (SVC)}

In the late 1970s, a solution based on power electronics switches was introduced to improve the PQ. The thyristor power switches took the main interest in that epoch and they were mainly used for the dynamic compensation. Some of the SVC structures are designed to combine several reactive elements that could be fixed or controlled by thyristor power switches. SVCs are well recognized to compensate both of NSCs and reactive power, but their main drawback is the production of harmonic content that results from the low switching frequency of the thyristor power switches [18]. The SVC installation can be accomplished via a step-down transformer at the PPS, as shown in Fig. 3, or at the secondary feeder sections of the V/V power transformer, i.e., the TPS.

The SVC is branded nowadays as a low-cost compensator because it may reduce the power factor of the system when it is designed for NSCs compensation. In other words, there is a tradeoff between power factor correction and NSCs compensation when using the SVC [4]. If the system carries reactive power, then the SVC cannot be a useful compensator. Therefore, the manufacturers nowadays are customizing the SVC to fit each customer with their specific needs, since there are various SVC types in the market.

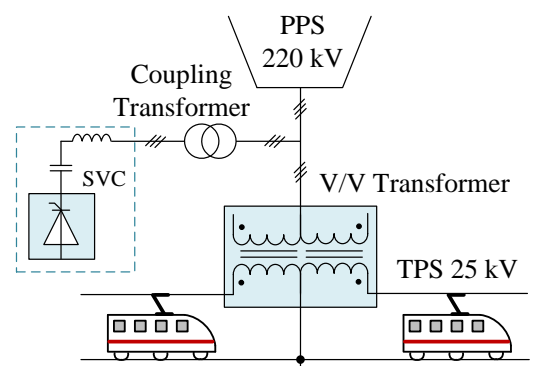

Fig. 3. SVC compensator connected to the PPS via a step-down transformer.

\section{B. Static Synchronous Compensator (STATCOM)}

During the last two decades, the insulated-gate bipolar transistor (IGBT) power switches have begun replacing the Thyristor based SVCs. Consequently, the static synchronous compensator (STATCOM) devices have been considered as the next-generation of the power compensators [2]. These devices consist of a voltage-source converter with a DC-link capacitor, coupling transformer and inductances installed on the AC side.

STATCOM devices can be used in medium voltage levels at the frequency of $50 \mathrm{~Hz}$ or $60 \mathrm{~Hz}$. Consequently, they are normally manufactured with a bigger volume in comparison to SVCs devices. Fig. 4 shows the STATCOM device connected in 
parallel with the PPS. This parallel connection signifies that the STATCOM can be connected or disconnected without disturbing the operation of the traction substation. Consequently, the robustness and readiness of the railway
In some countries, like Germany and Austria, the applied TPS frequency is $16.7 \mathrm{~Hz}$, where the SFC can be a useful choice since it has the advantage of frequency conversion [20]. Another SFC advantage in railway electrification is the

Table 1. Comparison between different compensator topologies in railway electrification.

\begin{tabular}{|c|c|c|c|c|c|c|c|}
\hline $\begin{array}{c}\text { POWER } \\
\text { COMPENSATOR }\end{array}$ & $\begin{array}{l}\text { HARMONICS } \\
\text { FILTERING }\end{array}$ & $\begin{array}{c}\text { NSC } \\
\text { COMPENSATION }\end{array}$ & $\begin{array}{l}\text { FREQUENCY } \\
\text { CONVERSION }\end{array}$ & $\begin{array}{c}\text { NeUtRAL } \\
\text { SECTIONS (NSS) }\end{array}$ & $\begin{array}{l}\text { OVERLOAD } \\
\text { CAPABILITY }\end{array}$ & $\begin{array}{c}\text { POWER RATING } \\
\text { (PER UNIT } \\
\text { LOAD) }[2]\end{array}$ & $\begin{array}{c}\text { PASSIVE } \\
\text { FILTER SIZE } \\
\text { ON PPS } \\
\end{array}$ \\
\hline SVC & No & Yes & No & Yes & $\mathrm{No}$ & $\approx 0.58$ & Large \\
\hline STATCOM & Yes & Yes & No & Yes & Yes & $\approx 0.58$ & Small \\
\hline $\mathrm{SFC}$ & Yes & Yes (inherent) & Yes & No & No & $=1.00$ & Small \\
\hline $\mathrm{RPC}$ & Yes & Yes & No & Can be omitted & Yes & $\approx 0.50$ & Small \\
\hline
\end{tabular}

substation will not be affected by the STATCOM operation. Moreover, the STATCOM does not require an internal power supplier, meaning that this device has a neutral contribution in terms of the active power. By another meaning, STATCOM will not consume active power, and its main objective is to exchange only reactive power with the PPS. As a result, the volt-ampere (VA) rate of the STATCOM can be significantly lower than the traction substation VA rate [19]. Compared to the SVC, STATCOM behaves as a bidirectional reactive power compensator, with a faster response time, larger load capability, lower harmonic contents and more compact design structure.

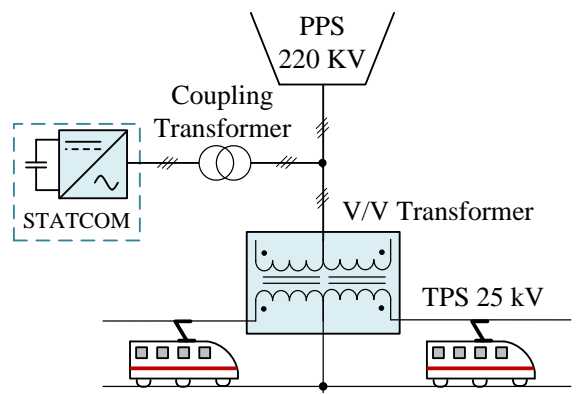

Fig. 4. STATCOM connected to the PPS via a step-down coupling transformer.

\section{Static Frequency Converter (SFC)}

The SFC consists of a three-phase AC/DC converter connected back-to-back to a single-phase DC/AC converter with a single DC-link as shown in Fig. 5. SFCs can prevent the harmonic currents to pass from the TPS into the PPS. In other words, the harmonics produced by locomotives do not pass into the PPS [20]. In addition, SFCs can easily overcome the problem of NSCs, since they can present the single-phase load on the TPS as a balanced three-phase load on the PPS [20]. Therefore, the harmonics and NSCs compensation are considered as an inherent behavior when using the SFC. If the catenary line is supplied by many SFCs, then they need to operate in all four quadrants and to have suitable power ratings to supply the full power required by the locomotives [2]. Comparing to the other power compensators like SVC, STATCOM and the rail power conditioner (RPC), the cost of the SFC system is significantly higher than the referred systems since it must be rated for a full train power, while the other power compensators must be rated only for a fraction of the load power [3]. continuous catenary line without any NSs. On the other hand, and since the V/V power transformer is not used in conjunction with SFC, the overload capability of this system is very limited comparing to the STATCOM and the RPC compensators [20]. In addition, two coupling transformers are required to interconnect the SFC between the different voltage levels of the PPS and the TPS. However, the new and innovative topologies are recommending the SFC based on the modular multilevel converter (MMC), which can be connected directly to the high voltage levels and dispensing the need of coupling transformers installation [20].

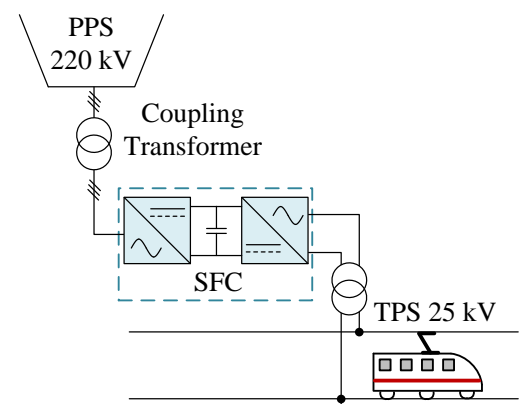

Fig. 5. SFC system in railway electrification.

\section{Rail Power Conditioner (RPC)}

RPC is a very effective topology to overcome the negative effects of currents NSCs and harmonics in electrified railways. Its structure contains two single-phase back-to-back converters with a single DC-link, as shown in Fig. 6. Each converter is connected to a load section through a step-down coupling transformer. The RPC can equalize the active power drawn by the main feeder two-phases of the TPS. This is possible by shifting half of the load active power difference from the highly loaded section to the lightly loaded one [5]. However, balancing the active power drawn by two phases is not enough to achieve balanced currents in the PPS. Therefore, the RPC also compensates the reactive power, where one of the RPC converters provides a capacitive reactive power while the other converter compensates an inductive reactive power [21]. Since the load power is mainly provided by the PPS through a V/V or a Scott power transformer, unlike the SFC, these devices cannot perform a frequency conversion but, on the other hand, the load sections can be overloaded as an advantage of using the $\mathrm{V} / \mathrm{V}$ 
power transformer [4]. In addition, problem of the NSs can be omitted by using a co-phase RPC system [3]. Table. 1 shows a comparison between the aforementioned compensator topologies in railway electrification. The new recommended RPC topologies are based on the MMC, so the two step-down coupling power transformers can be avoided [21].

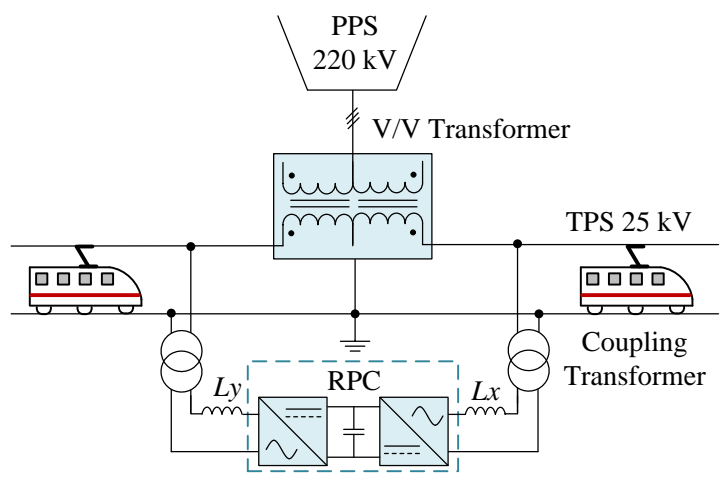

Fig. 6. RPC compensator connected to the TPS via step-down coupling transformers.

\section{CONCLUSION}

The nonlinear and dynamic characteristics of the high-speed electric locomotives can make the improvement of electric power quality (PQ) quite a difficult work. In this context, this paper presents the main PQ problems that can appear in railway electrification. Among the most serious ones are the negative sequence components of currents and the harmonic currents. The hazards associated to PQ deterioration are also discussed in this paper to demonstrate the importance of PQ improvement in railway electrification. The referred impacts can directly damage the electric power system, the signaling and communication systems, and the electric locomotive itself. Within the purpose of achieving PQ improvement, the conventional methods that have been used since the early use of railway electrification are also presented in this paper. In addition to this, and thanks to power electronics devices that can be dynamically controlled according to the behavior of the electric locomotives, the new power electronics technology-based methods are described and compared to each other to form a general overview about the main characteristics of each compensator.

\section{ACKNOWLEDGEMENT}

Mohamed Tanta was supported by FCT (Fundação para a Ciência e Tecnologia) PhD grant with a reference $\mathrm{PD} / \mathrm{BD} / 127815 / 2016$. This work has been supported by COMPETE: POCI-01-0145-FEDER-007043 and FCT within the Project Scope: UID/CEC/00319/2013.

\section{REFERENCES}

[1] Z. He, Z. Zheng, and H. Hu, "Power quality in high-speed railway systems," Int. J. Rail Transp., vol. 4, no. 2, pp.71-97, Apr. 2016. DOI: 10.1080/23248378.2016.1169228.

[2] I. Krastev, P. Tricoli, S. Hillmansen, and M. Chen, "Future of Electric Railways: Advanced Electrification Systems with Static Converters for ac Railways," IEEE Electrification Mag., vol. 4, no. 3, pp.6-14, Sep. 2016. DOI: 10.1109/MELE.2016.2584998.

[3] S. M. M. Gazafrudi, A. T. Langerudy, E. F. Fuchs, and K. Al-Haddad, "Power Quality Issues in Railway Electrification: A Comprehensive
Perspective," IEEE Trans. Ind. Electron., vol. 62, no. 5, pp.3081-3090, May 2015. DOI: 10.1109/TIE.2014.2386794.

[4] M. Tanta, J. A. Afonso, A. P. Martins, A. S. Carvalho, and J. L. Afonso, "Rail Power Conditioner Based on Indirect AC/DC/AC Modular Multilevel Converter Using a Three-phase V/V Power Transformer," in Lecture Notes in Engineering and Computer Science: Proceeding of the World Congress on Engineering, 5-7 July 2017, London, UK, pp.289-294.

[5] A. Luo, C. Wu, J. Shen, Z. Shuai, and F. Ma, "Railway Static Power Conditioners for High-speed Train Traction Power Supply Systems Using Three-phase V/V Transformers," IEEE Trans. Power Electron., vol. 26, no. 10, pp.2844-2856, Oct. 2011. DOI: 10.1109/TPEL.2011.2128888.

[6] D. Serrano-Jiménez, L. Abrahamsson, S. Castaño-Solís, and J. Sanz-Feito, "Electrical railway power supply systems: Current situation and future trends," Int. J. Electr. Power Energy Syst., vol. 92, pp.181-192, Nov. 2017. DOI: 10.1016/j.ijepes.2017.05.008.

[7] A. T. Langerudy, A. Mariscotti, and M. A. Abolhassani, "Power Quality Conditioning in Railway Electrification: A Comparative Study," IEEE Trans. Veh. Technol., vol. 66, no. 8, pp.6653-6662, Aug. 2017. DOI: 10.1109/TVT.2017.2661820.

[8] J. Li, M. Wu, and Q. Liu, "Measurement and simulation on low-frequency oscillation in the traction network of Xuzhou North Railway Hub," in 2016 12th World Congress on Intelligent Control and Automation (WCICA), 2016, pp.1797-1802. DOI: 10.1109/WCICA.2016.7578509.

[9] X. Jiang, H. Hu, Z. He, H. Tao, and Q. Qian, "Study on low-frequency voltage fluctuation of traction power supply system introduced by multiple modern trains," Electr. Power Syst. Res., vol. 146, pp.246-257, May 2017. DOI: 10.1016/j.epsr.2017.01.033.

[10] S. Midya, D. Bormann, A. Larsson, T. Schutte, and R. Thottappillil, "Understanding pantograph arcing in electrified railways - influence of various parameters," in 2008 IEEE International Symposium on Electromagnetic Compatibility, 2008, pp.1-6. DOI: 10.1109/ISEMC.2008.4652112.

[11] S. Midya, D. Bormann, T. Schutte, and R. Thottappillil, "Pantograph Arcing in Electrified Railways-Mechanism and Influence of Various Parameters-Part I: With DC Traction Power Supply," IEEE Trans. Power Deliv., vol. 24, no. 4, pp. 1931-1939, Oct. 2009, DOI: 10.1109/TPWRD.2009.2021035.

[12] Y. Hu, J. Huang, Z. Wang, and Y. Tao, "Research on the impact of electrified railway on power grid," in CICED 2010 Proceedings, pp.1-9.

[13] L. Abrahamsson, T. Schütte, and S. Östlund, "Use of converters for feeding of AC railways for all frequencies," Energy Sustain. Dev., vol. 16, no. 3, pp.368-378, Sep. 2012. DOI: 10.1016/j.esd.2012.05.003.

[14] M. Tanta, G. Pinto, V. Monteiro, A. P. Martins, A. S. Carvalho, and J. L. Afonso, "A Comprehensive Comparison of Rail Power Conditioners Based on Two-level Converters and a V/V Power Transformer in Railway Traction Power Systems," in Transport Research Arena (TRA) 2018 conference, Vienna, Austria, 16-Apr-2018. (Accepted for publication).

[15] C. Dai and Y. Sun, "Investigation of the Imbalance Current Compensation for Transformers Used in Electric Railways," in 2010 Asia-Pacific Power and Energy Engineering Conference, 2010, pp.1-4. DOI: 10.1109/APPEEC.2010.5448337.

[16] Z. Xu, L. Luo, Z. Zhang, and Y. Li, "A novel asymmetrical connection balance transformer for traction power supply,"Turk. J. Electr. Eng. Comput, Sci.,vol.23,no.5, p.1284, Aug.2015. DOI:10.3906/elk-1304-195.

[17] S. Yousefi, H. Biyouki, M. M, A. Zaboli, H. Askarian Abyaneh, and S. H. Hosseinian, "Harmonic Elimination of $25 \mathrm{kV}$ AC Electric Railways Utilizing a New Hybrid Filter Structure," AUT J. Electr. Eng., vol. 49, no. 1, pp.3-10, Jun. 2017. DOI: 10.22060/eej.2016.811.

[18] I. Perin, P. F. Nussey, U. M. Cella, T. V. Tran, and G. R. Walker, "Application of power electronics in improving power quality and supply efficiency of AC traction networks," in 2015 IEEE 11th International Conference on Power Electronics and Drive Systems, 2015, pp.10861094. DOI: 10.1109/PEDS.2015.7203421.

[19] J. G. Pinto, M. Tanta, V. Monteiro, L. A. M. Barros, and J. L. Afonso, "Active Power Conditioner Based on a Voltage Source Converter for Harmonics and Negative Sequence Components Compensation in Electrified Railway Systems," in Transport Research Arena (TRA) 2018 conference, Vienna, Austria, 16-Apr-2018. (Accepted for publication).

[20] M. Tanta, V. Monteiro, J. G. Pinto, A. P. Martins, A. S. Carvalho, and J. L. Afonso, "Efficiency and Cost Estimation for a Static Frequency Converter and a Rail Power Conditioner Based on an Indirect Modular Multilevel Converter in Railways Applications," in ICEE International 
Conference on Energy and Environment: Bringing Together Engineering and Economics, Porto, Portugal, 2017, pp.313-319.

[21] M. Tanta et al., "Simplified rail power conditioner based on a half-bridge indirect AC/DC/AC Modular Multilevel Converter and a V/V power transformer," in IECON 2017 - 43rd Annual Conference of the IEEE Industrial Electronics Society, 2017, pp.6431-6436. DOI: 10.1109/IECON.2017.8217120. 